\title{
Reliability of Foundation Pile Based on Settlement and a Parameter Sensitivity Analysis
}

\author{
Shujun Zhang, ${ }^{1,2}$ Luo Zhong, ${ }^{1}$ and Zhijun $\mathrm{Xu}^{3}$ \\ ${ }^{1}$ Wuhan University of Technology, School of Civil Engineering and Architecture, Wuhan 430070, China \\ ${ }^{2}$ Nanyang Institute of Technology, School of Civil Engineering, Nanyang 473004, China \\ ${ }^{3}$ Henan University of Technology, School of Civil Engineering and Architecture, Zhengzhou 450001, China
}

Correspondence should be addressed to Shujun Zhang; s-j-z668@163.com

Received 19 November 2015; Accepted 14 February 2016

Academic Editor: Egidijus R. Vaidogas

Copyright (C) 2016 Shujun Zhang et al. This is an open access article distributed under the Creative Commons Attribution License, which permits unrestricted use, distribution, and reproduction in any medium, provided the original work is properly cited.

\begin{abstract}
Based on the uncertainty analysis to calculation model of settlement, the formula of reliability index of foundation pile is derived. Based on this formula, the influence of coefficient of variation of the calculated settlement at pile head, coefficient of variation of the permissible limit of the settlement, coefficient of variation of the measured settlement, safety coefficient, and the mean value of calculation model coefficient on reliability is analyzed. The results indicate that (1) high reliability index can be obtained by increasing safety coefficient; (2) reliability index will be reduced with increasing of the mean value of calculation model coefficient and coefficient of variation of the permissible limit of settlement; (3) reliability index will not always monotonically increase or decrease with increasing of coefficient of variation of the calculated settlement and coefficient of variation of calculation model coefficient. To get a high reliability index, coefficient of variation of calculation model coefficient or value range of coefficient of variation of calculation model coefficient should be determined through the derived formula when values of other independent variables are determined.
\end{abstract}

\section{Introduction}

Analysis on reliability of foundation pile is one of the important research topics in the field of geotechnical engineering. In order to make in-depth research to this topic, experts and scholars have done a lot of work. But most of these researches are conducted based on bearing capacity of foundation pile $[1,2]$. Some theoretical methods which are used to analyze settlement of single foundation pile and foundation pile group have emerged so far such as load transfer method, integral equation method, finite element method, approximate analysis method, and hybrid analysis approach [3]. However, in these researches, parameter of soil property is basically considered as a fixed value. It is obviously limited because the soil mass is variable in space, there are many uncertainties in sample test, and the test data obtained from the testing site has very high variability. Thus, it has become a trend in analysis and research on settlement of foundation pile to take into account some variability parameters as variables and adopt uncertainty analysis method.
Bian [3], after analyzing the influence of spatial variability of soil mass on settlement of single foundation pile using random finite element method, pointed out that settlement of pile tip is influenced by uncertainty and randomness of parameter and then performed analysis to reliability of settlement of foundation pile by taking these uncertainties into account. Quek et al. [4] performed analysis to reliability of settlement of foundation pile using design drawing method based on uncertain parameters, and they also considered relationship between parameters as uncertainties. Zhang and $\mathrm{Ng}$ [5] investigated probability distribution of permissible limit of settlement under serviceability limit state of foundation pile using a large quantity of data they collected, laying a certain foundation for design of foundation pile under serviceability limit state from design based on certainty to reliability design. Zhang and Phoon [6] took into account all the uncertain factors when they research reliability design of foundation pile. They considered the measured settlement, estimated settlement, and permissible limit of settlement as random variables, thus giving the method for reliability 
design under serviceability limit state. Bian et al. [7] got formula of reliability of single pile under several common design methods of foundation pile and analyzed the influence of deviation factor of these several foundation pile design methods on the bearing capacity reliability of foundation pile. Bian et al. [8] got formula for reliability of foundation pile under ultimate limit state and serviceability limit state and studied the influence of randomness of allowable settlement of pile head on reliability analysis result under serviceability limit state. By combining failure probability of intact pile and pile which has sediment at the base; Li and Yan [9] obtained failure probability of single pile and got formula of deviation factor and coefficient of variation of foundation pile which has sediment at the base.

It can be seen from the above that research on reliability of settlement of foundation pile has become a focus in the field of engineering. However, the actual settlement of foundation pile is small and the difficulty for measurement is a little high. Meanwhile, the measurement result has large deviation and discreteness. All these above mentioned would influence the reliability index and make the investigation on the reliability index of foundation pile highly rich. Although a lot of formulas have been derived in the literature, and the effectiveness of these formulas has been proved through some testing data, it is still necessary and beneficial to recognize sensitive parameters in many affecting variables. In this paper, formula of reliability index of settlement of foundation pile (single pile) is derived through the establishment of limit state equation based on uncertainty analysis on settlement model of foundation pile. The influence of coefficient of variation of the calculated settlement, coefficient of variation of the permissible limit of settlement, and coefficient of variation of the measured settlement on reliability is studied as well. The result of analysis can be used as reference and guide for design, construction, and quality inspection of foundation pile engineering.

\section{Model Coefficient and Limit State Equation}

Load transfer method is a commonly used method to calculate settlement of a foundation pile. It divides the foundation pile into several elastic units. It is assumed that each unit is connected with the soil mass (including pile tip) through nonlinear spring to simulate load transfer mechanism between foundation pile and soil. Nonlinearity of interaction between foundation pile and soil as well as stratification characteristic of soil can be correctly described through this method, which is suitable for calculation of settlement of single pile. However, continuity of soil property is not fully considered in this method [10].

As one of the difficult problems in foundation pile engineering, settlement estimation of foundation pile is influenced by many uncertainties, such as physical dimension of pile body, pile formation technology, property of soil around the pile, and measurement error [11]. Thus, the calculation result of settlement of foundation pile is of high uncertainty. Under vertical load, the measured settlement of pile head is assumed to be $S_{m}$ and the estimated settlement of pile head according to settlement formula of foundation pile is $S_{p}$. The calculated settlement of pile head $S_{p}$ is considered as a random variable to reflect uncertainty of calculation model of settlement.

In order to make quantitative evaluation to uncertainty of calculation model of settlement, the ratio of the measured settlement $S_{m}$ to the calculated one $S_{p}$ is used to define model coefficient:

$$
\lambda_{s}=\frac{S_{m}}{S_{p}} .
$$

Then, the uncertainty of calculation model of foundation pile can be described through the mean value and the coefficient of variation of $\lambda_{s}$.

$\mathrm{Xu}$ [12] collected static load test data of 60 foundation piles with $\mathrm{H}$-type steel frame and studied its settlement property by nonlinear load transfer method. After statistical analysis, the mean value of calculation model $\lambda_{s}$ and coefficient of variation were arrived: that is, $\mu_{\lambda_{s}}=1.25$ and $\mathrm{COV}_{\lambda_{s}}=0.23$.

In addition, under the influence of site environment, construction condition, measurement equipment, and test technology, the permissible limit of settlement $S_{\text {tol }}$ and the measured settlement $S_{m}$ are of highly uncertain. Therefore, the permissible limit of settlement $S_{\text {tol }}$ and the measured settlement $S_{m}$ are considered as random variables in reliability analysis of settlement of foundation pile.

Vertical settlement of pile head cannot exceeds the permissible limit of settlement $S_{\text {tol }}$ under normal working condition. A function can be established according to the permissible limit of settlement $S_{\text {tol }}$ and the measured settlement $S_{m}$ :

$$
g\left(S_{\text {tol }}, S_{m}\right)=S_{\text {tol }}-S_{m}
$$

A two-dimensional state space is established through formula (2), which takes the permissible limit of settlement $S_{\text {tol }}$ and the measured settlement $S_{m}$ as the variables, wherein

(1) $g\left(S_{\text {tol }}, S_{m}\right)=S_{\text {tol }}-S_{m}=0$ means that foundation pile reaches the limit state under the working vertical load, which is the critical state. It can be used as the limit state curve, dividing the entire state space into security domain and failure domain;

(2) $g\left(S_{\text {tol }}, S_{m}\right)=S_{\text {tol }}-S_{m}>0$ indicates that foundation pile is in a safe state and the representative domain is a security domain;

(3) $g\left(S_{\text {tol }}, S_{m}\right)=S_{\text {tol }}-S_{m}<0$ means that foundation pile is in a failure state and the representative domain is a failure domain.

In order to effectively make reliability analysis of the settlement with probability method, distribution pattern of the permissible limit of settlement $S_{\text {tol }}$ and the measured settlement $S_{m}$ should be determined. The scholars have made a lot of investigations on this topic. Zhang and $\mathrm{Xu}$ [13] researched the vertical settlement of pile head of 149 foundation piles into which $\mathrm{H}$-steel is inserted under static 
load test condition and analyzed relevant results using loadsettlement model of foundation pile. Zhang and Phoon [6] took logarithmic normal distribution as the distribution pattern of the measured settlement $S_{m}$ of pile head in their researches. Zhang and $\mathrm{Ng}$ [5] collected a huge mass of data about settlement of foundation pile of bridge. By using statistical analysis method, they found that a logarithmic normal distribution can be used for the permissible limit of settlement $S_{\text {tol }}$.

\section{Calculation of Reliability Index}

According to (2), if the measured settlement $S_{m}$ is greater than the permissible limit of settlement $S_{\text {tol }}$, the foundation pile is invalid and cannot meet the design requirement of foundation pile engineering.

Let $p_{f}$ and $\beta$ represent the failure probability of foundation pile due to settlement and the corresponding reliability index, respectively. According to knowledge of mathematical statistics and reliability theory $[14,15]$, relation between failure probability and reliability index reads

$$
p_{f}=\operatorname{Prob}\left(S_{\mathrm{tol}}<S_{m}\right)=\Phi(-\beta)
$$

wherein $\Phi(\cdot)$ is the cumulative probability distribution function of the standard normal distribution.

According to the existing research data, the permissible limit of settlement $S_{\text {tol }}$, the measured settlement $S_{m}$, and model coefficient $\lambda_{s}$ are assumed to obey the logarithmic normal distribution. Then the failure probability of a foundation pile can be written in

$$
\begin{aligned}
p_{f} & =\operatorname{Prob}\left(S_{\mathrm{tol}}<S_{m}\right)=\operatorname{Prob}\left(\frac{S_{\mathrm{tol}}}{S_{m}}<1\right) \\
& =\operatorname{Prob}\left[\ln \left(\frac{S_{\mathrm{tol}}}{S_{m}}\right)<0\right] \\
& =\operatorname{Prob}\left\{\ln \left[\left(\frac{S_{\mathrm{tol}}}{S_{p}}\right) \times\left(\frac{S_{p}}{S_{m}}\right)\right]<0\right\} \\
& =\operatorname{Prob}\left\{\ln \left[\frac{\left(S_{\mathrm{tol}} / S_{p}\right)}{\lambda_{s}}\right]<0\right\} \\
& =\operatorname{Prob}\left[\ln \left(S_{\mathrm{tol}}\right)-\ln \left(S_{p}\right)-\ln \left(\lambda_{s}\right)<0\right] \\
& =\Phi\left(-\frac{\mu_{S_{\mathrm{tol}}^{N}}-\mu_{S_{p}^{N}}-\mu_{\lambda_{s}^{N}}}{\sqrt{\sigma_{S_{\mathrm{tol}}^{N}}^{2}+\sigma_{S_{p}^{N}}^{2}+\sigma_{\lambda_{s}^{N}}^{2}}}\right)
\end{aligned}
$$

wherein $\mu_{S_{\text {tol }}^{N}}, \mu_{S_{p}^{N}}$, and $\mu_{\lambda_{s}^{N}}$ are the mean value of $\ln \left(S_{\text {tol }}\right)$, $\ln \left(S_{p}\right)$ and $\ln \left(\lambda_{s}\right)$, respectively. While $\sigma_{S_{\text {tol }}^{N}}, \sigma_{S_{p}^{N}}$, and $\sigma_{\lambda_{s}^{N}}$ are standard deviation of $\ln \left(S_{\text {tol }}\right), \ln \left(S_{p}\right)$, and $\ln \left(\lambda_{s}\right)$, respectively.

According to (3) and (4), the reliability index $\beta$ of foundation pile based on settlement analysis is

$$
\begin{aligned}
\beta= & \frac{\mu_{S_{\mathrm{tol}}^{N}}-\mu_{S_{p}^{N}}-\mu_{\lambda_{s}^{N}}}{\sqrt{\sigma_{S_{\mathrm{tol}}^{N}}^{2}+\sigma_{S_{p}^{N}}^{2}+\sigma_{\lambda_{s}^{N}}^{2}}}=\frac{\ln \left[\mu_{S_{\mathrm{tol}}} / \sqrt{1+\mathrm{COV}_{S_{\mathrm{tol}}}^{2}}\right]-\ln \left[\mu_{S_{p}} / \sqrt{1+\mathrm{COV}_{S_{p}}^{2}}\right]-\ln \left[\mu_{\lambda_{s}} / \sqrt{1+\mathrm{COV}_{\lambda_{s}}^{2}}\right]}{\sqrt{\ln \left[\left(1+\mathrm{COV}_{S_{\mathrm{tol}}}^{2}\right)\left(1+\mathrm{COV}_{S_{p}}^{2}\right)\left(1+\mathrm{COV}_{\lambda_{s}}^{2}\right)\right]}} \\
= & \frac{\ln \left[\left(\mathrm{FS} / \mu_{\lambda_{s}}\right) \sqrt{\left.\left(1+\mathrm{COV}_{S_{p}}^{2}\right)\left(1+\mathrm{COV}_{\lambda_{s}}^{2}\right) /\left(1+\mathrm{COV}_{S_{\mathrm{tol}}}^{2}\right)\right]}\right.}{\sqrt{\ln \left[\left(1+\mathrm{COV}_{S_{\mathrm{tol}}}^{2}\right)\left(1+\mathrm{COV}_{S_{p}}^{2}\right)\left(1+\mathrm{COV}_{\lambda_{s}}^{2}\right)\right]}}
\end{aligned}
$$

wherein $\mu_{S_{\text {tol }}}, \mu_{S_{p}}$, and $\mu_{\lambda_{s}}$ are the mean value of variables $S_{\text {tol }}$, $S_{p}$, and $\lambda_{s}$, respectively; $\mathrm{COV}_{S_{\text {tol }}}$, $\mathrm{COV}_{S_{p}}$, and $\mathrm{COV}_{\lambda_{s}}$ are the variable coefficient of variables $S_{\text {tol }}, S_{p}$, and $\lambda_{s}$, respectively; FS is safety coefficient defined by

$$
\mathrm{FS}=\frac{\mu_{S_{\mathrm{tol}}}}{\mu_{S_{p}}} .
$$

In the investigation of settlement, Skempton and MacDonald [16] suggested that the basic safety coefficient should not be lower than 1.25 for differential settlement and maximum settlement and that the safety coefficient should not be lower than 1.50 for buildings under torsion. Thus, reliability analysis of foundation pile based on characteristic of settlement should use higher safety coefficient.

According to (1),

$$
S_{m}=\lambda_{s} S_{p}
$$

Based on (7), we assume that $\lambda_{s}$ and $S_{p}$ are uncorrelated. The statistical characteristic of the measured settlement $S_{m}$ of pile head can be estimated by

$$
\begin{aligned}
\mu_{S_{m}} & =\mu_{\lambda_{s}} \mu_{S_{p}}, \\
\operatorname{COV}_{S_{m}} & =\sqrt{\operatorname{COV}_{S_{p}}^{2}+\mathrm{COV}_{\lambda_{s}}^{2}} .
\end{aligned}
$$

\section{Parameter Sensitivity Analysis}

According to (5), the settlement reliability of foundation pile is influenced by safety coefficient FS, the mean value $\mu_{\lambda_{s}}$ of calculation model coefficient, coefficient of variation $\mathrm{COV}_{S_{\text {tol }}}$ of the permissible limit of settlement of foundation pile, coefficient of variation $\mathrm{COV}_{S_{p}}$ of the calculated settlement of foundation pile, and coefficient of variation $\mathrm{COV}_{\lambda_{s}}$ of calculation model coefficient. Thus, it is difficult to 
determine settlement reliability of foundation pile. However, the influence of each parameter on reliability index can be recognized through parameter sensitivity analysis, and then high reliability domain and low reliability domain can be obtained, which can be used as reference in engineering.
4.1. Influence of Coefficient of Variation of the Permissible Limit of Settlement. According to (5),

$$
\begin{aligned}
\frac{\partial \beta}{\partial \operatorname{COV}_{S_{\text {tol }}}}= & -\frac{\operatorname{COV}_{S_{\text {tol }}}}{\left(1+\operatorname{COV}_{S_{\text {tol }}}^{2}\right) \sqrt{\ln \left[\left(1+\operatorname{COV}_{S_{\text {tol }}}^{2}\right)\left(1+\mathrm{COV}_{S_{p}}^{2}\right)\left(1+\mathrm{COV}_{\lambda_{s}}^{2}\right)\right]}} \\
& -\frac{\operatorname{COV}_{S_{\text {tol }}} \ln \left(\left(\mathrm{FS} / \mu_{\lambda_{s}}\right) \sqrt{\left(1+\mathrm{COV}_{S_{p}}^{2}\right)\left(1+\mathrm{COV}_{\lambda_{s}}^{2}\right) /\left(1+\mathrm{COV}_{S_{\mathrm{tol}}}^{2}\right)}\right.}{\left(1+\mathrm{COV}_{S_{\mathrm{tol}}}^{2}\right)\left(\ln \left[\left(1+\mathrm{COV}_{S_{\mathrm{tol}}}^{2}\right)\left(1+\mathrm{COV}_{S_{p}}^{2}\right)\left(1+\mathrm{COV}_{\lambda_{s}}^{2}\right)\right]\right)^{3 / 2}}
\end{aligned}
$$

According to the scope of independent variable and formula (5), $\partial \beta / \partial \mathrm{COV}_{S_{\text {tol }}}$ is constantly smaller than 0 . Thus, the reliability index will always decrease with the increase of the coefficient of variation of the permissible limit of settlement of foundation pile.

Figure 1, based on formula (5), shows the influence of the permissible limit of settlement of foundation pile on reliability index in the circumstance of a set of special parameters, wherein $\mathrm{FS}=3.0, \mu_{\lambda_{s}}=1.25$, and $\mathrm{COV}_{\lambda_{s}}=0.23$.

It can be seen that, with the increase of the coefficient of variation of the permissible limit of settlement, reliability index gradually decreases, which is consistent with the law given by (9). In the particular condition given in Figure 1, a greater reliability index can be obtained when coefficient of variation $\mathrm{COV}_{\mathrm{tol}}$ of the permissible limit of settlement is between 0.0 and 0.4 , and coefficient of variation $\mathrm{COV}_{S_{p}}$ of the measured settlement is near zero. In this domain, however, reliability index will be significantly changed when $\mathrm{COV}_{\text {tol }}$ changes within $0.0-0.4$.

4.2. Influence of Coefficient of Variation of Calculation Model Coefficient. In a similar way, from (5)

$$
\begin{aligned}
\frac{\partial \beta}{\partial \operatorname{COV}_{\lambda_{s}}}= & \frac{\operatorname{COV}_{\lambda_{s}}}{\left(1+\mathrm{COV}_{\lambda_{s}}^{2}\right) \sqrt{\ln \left[\left(1+\mathrm{COV}_{S_{\mathrm{tol}}}^{2}\right)\left(1+\mathrm{COV}_{S_{p}}^{2}\right)\left(1+\mathrm{COV}_{\lambda_{s}}^{2}\right)\right]}} \\
& -\frac{\mathrm{COV}_{\lambda_{s}} \ln \left(\left(\mathrm{FS} / \mu_{\lambda_{s}}\right) \sqrt{\left(1+\mathrm{COV}_{S_{p}}^{2}\right)\left(1+\mathrm{COV}_{\lambda_{s}}^{2}\right) /\left(1+\mathrm{COV}_{S_{\mathrm{tol}}}^{2}\right)}\right)}{\left(1+\mathrm{COV}_{S_{p}}^{2}\right)\left(\ln \left[\left(1+\mathrm{COV}_{S_{\mathrm{tol}}}^{2}\right)\left(1+\mathrm{COV}_{S_{p}}^{2}\right)\left(1+\mathrm{COV}_{\lambda_{s}}^{2}\right)\right]\right)^{3 / 2}} .
\end{aligned}
$$

It can be seen from formula (10) that the sign of $\partial \beta / \partial \mathrm{COV}_{\lambda}$ is related to the value of the independent variables: that is, the reliability index can increase and decrease with the increase of the coefficient of variation of calculation model coefficient. The reliability index reaches its maximum value when the value of $\operatorname{COV}_{\lambda_{s}}$ meets $\partial^{2} \beta / \partial^{2} \operatorname{COV}_{\lambda_{s}}=0$. In the real engineering, (10) can be used as a guidance for obtaining high reliability index. For example, the sign of $\partial \beta / \partial \mathrm{COV}_{\lambda_{s}}$ can be determined using formula (10) when the safety coefficient FS, the mean value $\mu_{\lambda_{s}}$ of calculation model coefficient and coefficient of variation $\mathrm{COV}_{\text {tol }}$ of the permissible limit of settlement are known. Subsequently, this result can be used to determine the range of independent variable (coefficient of variation $\mathrm{COV}_{\lambda_{s}}$ of calculation model coefficient and coefficient of variation $\mathrm{COV}_{S_{p}}$ of the measured settlement) which can make the reliability reaches the desired level.
According to (5), the influence of coefficient of variation of calculation model coefficient on reliability index under this set of special circumstance can be obtained taking $\mathrm{COV}_{\lambda_{s}}$ as $0.0,0.2,0.4,0.6,0.8$, and 1.0 in sequence, $\mathrm{FS}=3.0, \mu_{\lambda_{\mathrm{s}}}=1.25$, and $\mathrm{COV}_{\text {tol }}=0.583$, and taking coefficient of variation of the measured settlement as independent variable. The calculation result is as shown in Figure 2.

It can be seen from Figure 2 that reliability index does not continuously decrease with increasing of coefficient of variation of calculation model coefficient. Reliability index increases with increasing of coefficient of variation of calculation model coefficient when coefficient of variation $\mathrm{COV}_{S_{p}}$ of the measured settlement is greater than 0.9. This is consistent with the law given by (10). At the same time, when $\mathrm{COV}_{\lambda_{\mathrm{s}}}$ changes within $[0,1]$, reliability index is only in the variation 
region $[1.06,1.32]$. This indicates that the change of coefficient of variation of calculation model coefficient does not significantly influence reliability index under the particular circumstance of this set of parameter representative.
4.3. Influence of Coefficient of Variation of the Measured Settlement. From (5),

$$
\begin{aligned}
\frac{\partial \beta}{\partial \operatorname{COV}_{S_{p}}}= & \frac{\operatorname{COV}_{S_{p}}}{\left(1+\operatorname{COV}_{S_{p}}^{2}\right) \sqrt{\ln \left[\left(1+\mathrm{COV}_{S_{\mathrm{tol}}}^{2}\right)\left(1+\mathrm{COV}_{S_{p}}^{2}\right)\left(1+\mathrm{COV}_{\lambda_{s}}^{2}\right)\right]}} \\
& -\frac{\operatorname{COV}_{S_{p}} \ln \left(\left(\mathrm{FS} / \mu_{\lambda_{s}}\right) \sqrt{\left(1+\mathrm{COV}_{S_{p}}^{2}\right)\left(1+\mathrm{COV}_{\lambda_{s}}^{2}\right) /\left(1+\mathrm{COV}_{S_{\mathrm{tol}}}^{2}\right)}\right)}{\left(1+\mathrm{COV}_{S_{p}}^{2}\right)\left(\ln \left[\left(1+\mathrm{COV}_{S_{\mathrm{tol}}}^{2}\right)\left(1+\mathrm{COV}_{S_{p}}^{2}\right)\left(1+\mathrm{COV}_{\lambda_{s}}^{2}\right)\right]\right)^{3 / 2}} .
\end{aligned}
$$

It can be seen from (11) that the sign of $\partial \beta / \partial \mathrm{COV}_{S_{p}}$ is related to the value of the independent variables: that is, reliability index can increase and decrease with the increase of coefficient of variation of the measured settlement. This result is similar to the value of $\partial \beta / \partial \operatorname{COV}_{\lambda_{s}}$. In real engineering, the sign of $\partial \beta / \partial \mathrm{COV}_{S_{p}}$ can be determined using (11) when the safety coefficient FS, the mean value $\mu_{\lambda_{s}}$ of calculation model coefficient, and coefficient of variation $\mathrm{COV}_{\text {tol }}$ of the permissible limit of settlement are known. This result can also be used to determine the range of independent variable (coefficient of variation $\mathrm{COV}_{\lambda_{s}}$ of calculation model coefficient and coefficient of variation $\mathrm{COV}_{S_{p}}$ of the measured settlement) which can make the reliability reaches the desired level.

It can also be seen from the particular case shown in Figures 1 and 2 that coefficient of variation $\mathrm{COV}_{S_{p}}$ of the measured settlement has influence on the reliability index and that the reliability index can increase and decrease with the increase of $\mathrm{COV}_{S_{p}}$, which is consistent with the law given by (11).

\subsection{Influence of Safety Coefficient. According to (5),}

$$
\begin{aligned}
& \frac{\partial \beta}{\partial \mathrm{FS}} \\
& =\frac{1}{\mathrm{FS} \sqrt{\ln \left[\left(1+\mathrm{COV}_{S_{\mathrm{tol}}}^{2}\right)\left(1+\mathrm{COV}_{S_{p}}^{2}\right)\left(1+\mathrm{COV}_{\lambda_{s}}^{2}\right)\right]}} .
\end{aligned}
$$

Since the independent variables in formula (12) are greater than 0 , we can easily know that $\partial \beta / \partial \mathrm{FS}>0$, which means reliability index will always increase with the increase of the safety coefficient.

Figure 3, based on (5), shows the influence of the safety coefficient on the reliability index in the circumstance of a set of special parameter: that is, $\operatorname{COV}_{\lambda_{s}}=0.23, \mu_{\lambda_{s}}=1.25$, and $\mathrm{COV}_{\text {tol }}=0.583$. It can be seen that the law given by Figure 3 is consistent with that by (12) and that the reliability index always increases with safety coefficient.
4.5. Influence of the Mean Value of Calculation Model Coefficient. According to (5),

$$
\begin{aligned}
& \frac{\partial \beta}{\partial \mu_{\lambda_{s}}} \\
& =-\frac{1}{\mu_{\lambda_{s}} \sqrt{\ln \left[\left(1+\mathrm{COV}_{S_{\text {tol }}}^{2}\right)\left(1+\mathrm{COV}_{S_{p}}^{2}\right)\left(1+\mathrm{COV}_{\lambda_{s}}^{2}\right)\right]}} .
\end{aligned}
$$

In a similarly way, independent variables in formula (13) are greater than 0 , and thus $\partial \beta / \partial \mu_{\lambda_{s}}<0$, which means that the increase of the mean value of calculation model coefficient reduces the reliability index.

According to (5), the influence of the mean value of calculation model coefficient on reliability index under this particular condition can be obtained taking $\mathrm{COV}_{\lambda_{s}}=0.23$, $\mathrm{COV}_{\text {tol }}=0.583$, FS $=3.0$, and $\mathrm{COV}_{S_{p}}=0.5$, as shown in Figure 4 . It can be seen that reliability index continuously reduces with the increase of the mean value of calculation model coefficient, which is consistent with the conclusion obtained through (13).

\section{Analysis of Discussion Result}

It can be seen from (9) and Figure 1 that the lower the coefficient of variation of the permissible limit of settlement is, the greater the reliability index is, and ideal reliability index can be obtained when coefficient of variation of the permissible limit of settlement takes value from 0 to 0.2 . It indicates that it is easier to obtain high reliability index when discreteness of the permissible limit of settlement is small. In real engineering, it is very important engineering value to try to obtain accurate permissible limit of settlement.

The result shown in (12) and Figure 3 indicates that reliability index can be improved when safety coefficient is increased, which means that it has a clear positive significance to improve reliability index of engineering using greater safety coefficient in engineering practice.

Formula (13) and Figure 4 show that high reliability index can be obtained with a low mean value of calculation model coefficient. This indicates that it is easier to obtain high reliability index when the ratio of the measured settlement 


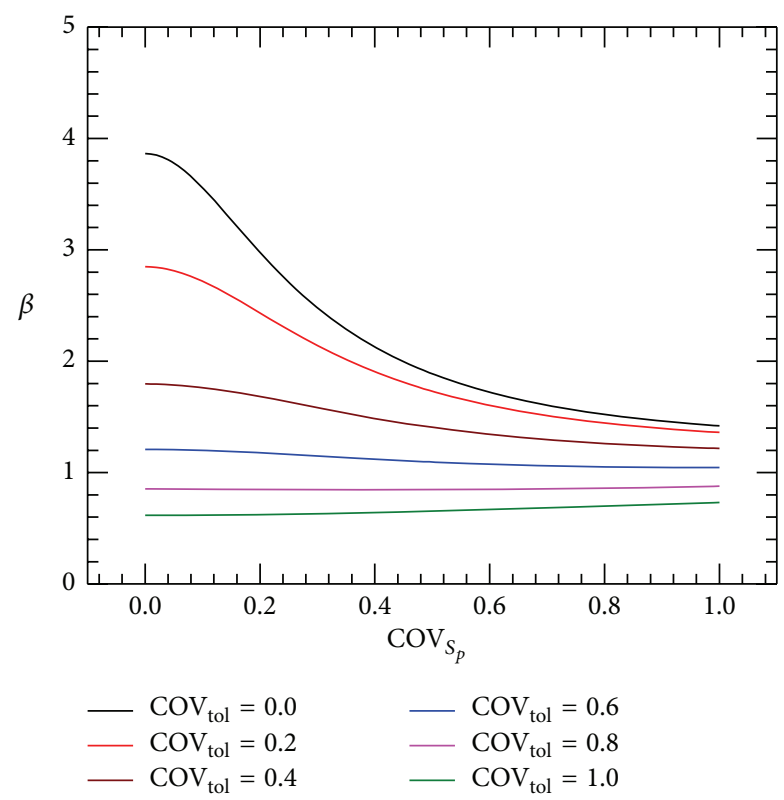

FIgURE 1: Relation between reliability index $\beta$ and coefficient of variable $\mathrm{COV}_{\text {tol }}$.

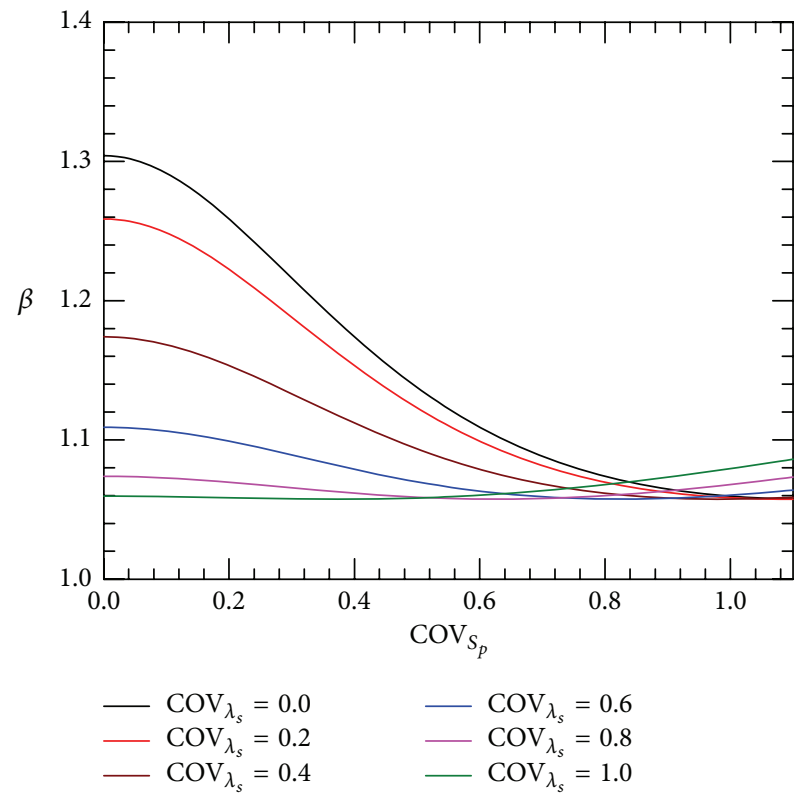

Figure 2: Relation between reliability index $\beta$ and coefficient of variable $\mathrm{COV}_{\lambda_{s}}$.

value to the calculated settlement value is small, which obviously agrees with the logic and the practical engineering. It means that we should try our best to obtain detailed settlement observation data to reduce the ratio of the measured settlement value to the calculated settlement value and finally improve the reliability index.

Formulas (10) and (11) indicate that partial derivative of the reliability index to the coefficient of variation of the calculated settlement and the coefficient of variation of calculation model coefficient can be great than 0 or less than 0 , which

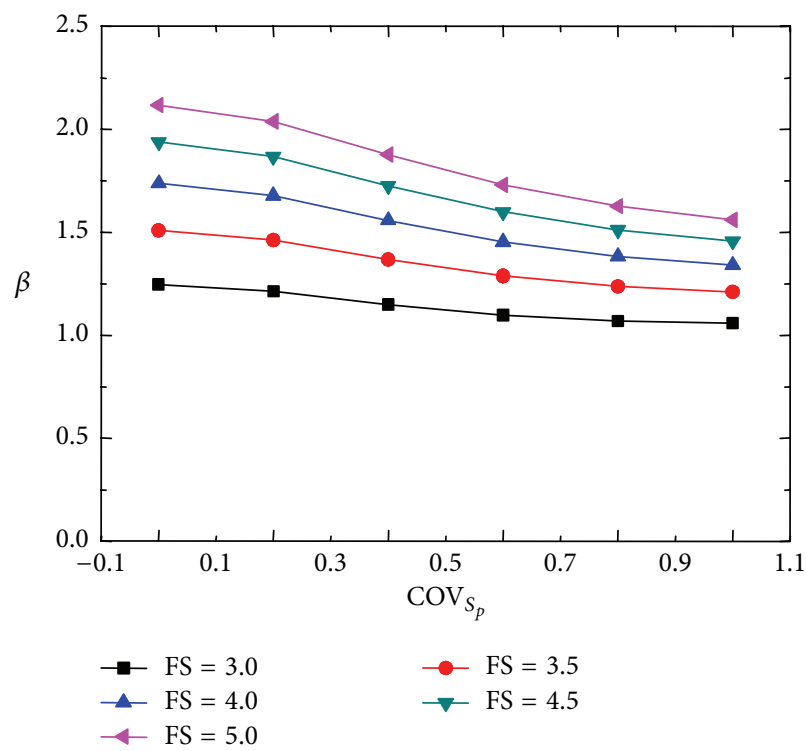

FIgURE 3: Relation between reliability index $\beta$ and coefficient of variable $\mathrm{COV}_{S_{p}}$.

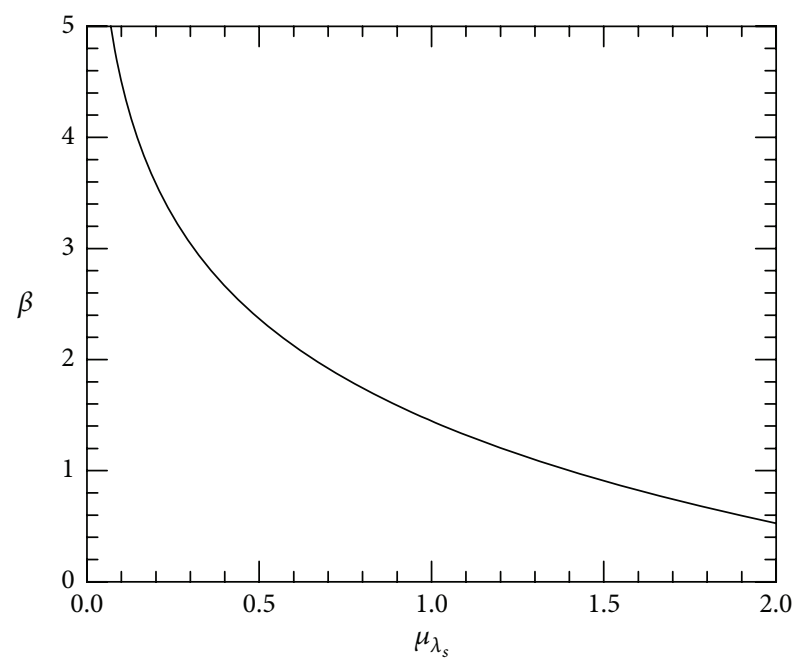

FIGURE 4: Relation between reliability index $\beta$ and the mean value of calculation model coefficient.

means that reliability index will not always monotonically increase or decrease with increasing of coefficient of variation of the calculated settlement and coefficient of variation of calculation model coefficient. Instead, it increases sometimes and then decreases in the other cases. This can be seen from the particular circumstance shown in Figures 1 and 2. Therefore, to get a high reliability index, coefficient of variation of calculation model coefficient or value range of coefficient of variation of calculation model coefficient should be determined through the derived formula when values of other independent variables are determined. 


\section{Conclusion}

In this paper, based on analysis to settlement of foundation pile, limit state equations are established. Formula for reliability index of foundation pile settlement is derived, and a parameter sensitivity analysis is conducted. The following conclusion can be arrived:

(1) With the increase of the coefficient of variation of the permissible limit of settlement, the reliability index gradually reduces.

(2) Gradual increase of the reliability index can be obtained by the increase of the safety coefficient.

(3) The reliability index always decreases with the increase of the mean value of calculation model coefficient.

(4) Reliability index will not always monotonically increase or decrease with the increase of the coefficient of variation of the calculated settlement and the coefficient of variation of calculation model coefficient.

\section{Conflict of Interests}

The authors declare that there is no conflict of interests regarding the publication of this paper.

\section{Acknowledgments}

Thanks are due to the National Natural Science Foundation of China (51178165), High-Level Talent Fund Program of Henan University of Technology (2013BS010), and Henan Basic and Cutting-Edge Technology Research Plan Program (132300410024) for supporting the present work.

\section{References}

[1] E. Momeni, R. Nazir, D. Jahed Armaghani, and H. Maizir, "Prediction of pile bearing capacity using a hybrid genetic algorithm-based ANN," Measurement, vol. 57, pp. 122-131, 2014.

[2] F. Milad, T. Kamal, H. Nader, and O. E. Erman, "New method for predicting the ultimate bearing capacity of driven piles by using Flap number," KSCE Journal of Civil Engineering, vol. 19, no. 3, pp. 611-620, 2015.

[3] X. Y. Bian, Reliability Analysis and Design of Pile Foundations for Serviceability Limit State, Huazhong University of Science and Technology, Wuhan, China, 2014 (Chinese).

[4] S. T. Quek, Y. K. Chow, and K. K. Phoon, "Further contributions to reliability-based pile settlement analysis," Journal of Geotechnical Engineering, vol. 118, no. 5, pp. 726-742, 1992.

[5] L. M. Zhang and A. M. Y. Ng, "Probabilistic limiting tolerable displacements for serviceability limit state design of foundations," Geotechnique, vol. 55, no. 2, pp. 151-161, 2005.

[6] L. Zhang and K. Phoon, "Serviceability considerations in reliability-based foundation design," Foundation Analysis and Design: Innovative Methods, GSP 153, pp. 127-136, 2006.

[7] X.-Y. Bian, J.-J. Zheng, and Z.-J. Xu, "Reliability analysis of bearing capacity of foundation piles considering pile foundation design approach," Chinese Journal of Geotechnical Engineering, vol. 35, no. 2, pp. 1099-1102, 2013 (Chinese).
[8] X.-Y. Bian, J.-J. Zheng, and Z.-J. Xu, "Reliability analysis of serviceability limit state of foundation piles considering uncertainties of parameter and model," Rock and Soil Mechanics, vol. 35, no. 11, pp. 3317-3322, 2014 (Chinese).

[9] D.-Q. Li and L.-L. Yan, "Reliability evaluation of bored pile considering possibility of toe debris presence," Rock and Soil Mechanics, vol. 29, no. 1, pp. 155-160, 2008.

[10] M.-H. Zhao, D. Zou, and X.-J. Zou, "Settlement calculation of pile groups by load transfer method," Engineering Mechanics, vol. 23, no. 7, pp. 119-123, 2006.

[11] M.-H. Zhao, D. Zou, and X.-J. Zou, "Settlement calculation of pile foundations with elevated caps by load transfer method," Chinese Journal of Rock Mechanics and Engineering, vol. 24, no. 13, pp. 2310-2314, 2005.

[12] Y. Xu, Calibration of Settlement Analysis Models for Single Piles and Pile Groups, Hong Kong University of Science and Technology, Hong Kong, 2006.

[13] L. Zhang and Y. Xu, "Settlement of building foundations based on field pile load tests," in Proceedings of the 16th International Conference on Soil Mechanics and Geotechnical Engineering (ICSMGE '05), pp. 2871-2874, Osaka, Japan, September 2005.

[14] A. H.-S. Ang and W. H. Tang, Probability Concepts in Engineering: Emphasis on Applications to Civil and Environmental Engineering, John Wiley \& Sons, New York, NY, USA, 2nd edition, 2007.

[15] G. B. Baecher and J. T. Christian, Reliability and Statistics in Geotechnical Engineering, John Wiley \& Sons, Chichester, UK, 2003.

[16] A. W. Skempton and D. H. MacDonald, "The allowable settlement of buildings," Proceedings of the Institution of Civil Engineers, vol. 3, no. 5, pp. 727-768, 1956. 


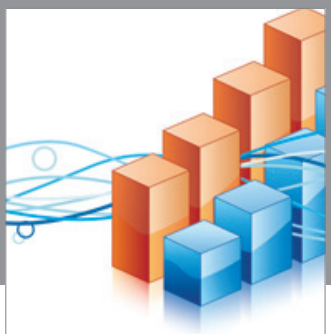

Advances in

Operations Research

vatem alat4

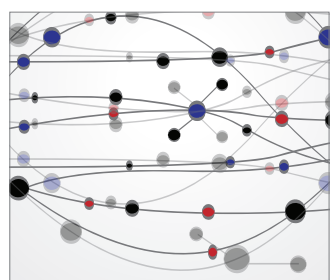

\section{The Scientific} World Journal
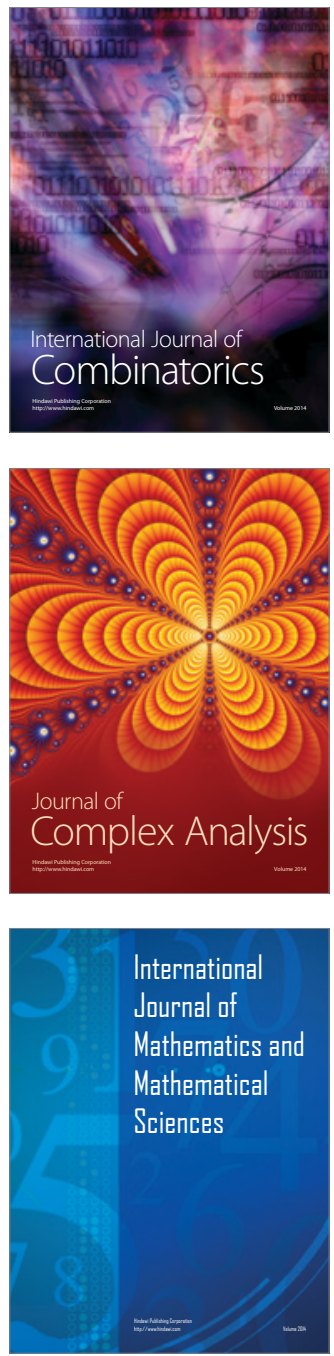
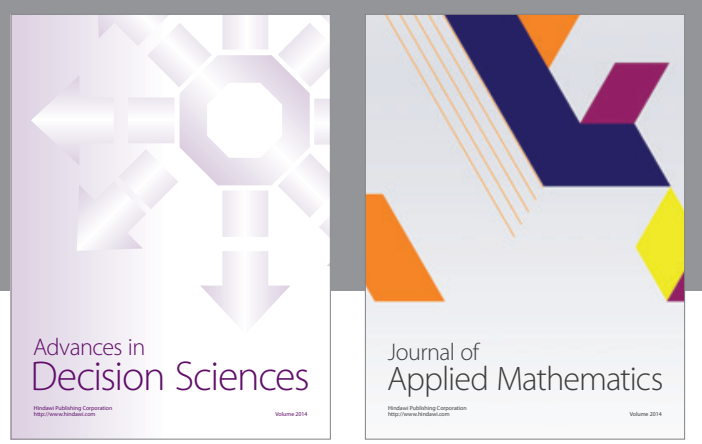

Algebra

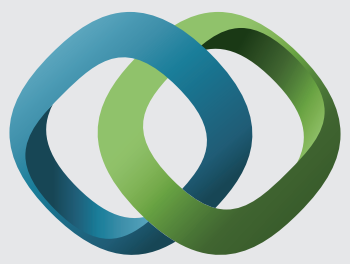

\section{Hindawi}

Submit your manuscripts at

http://www.hindawi.com
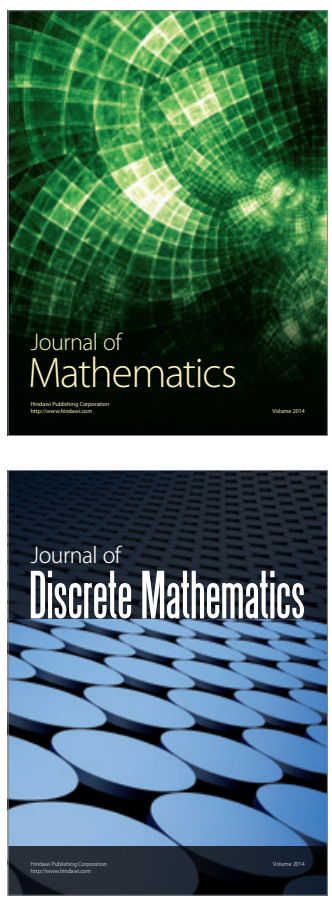

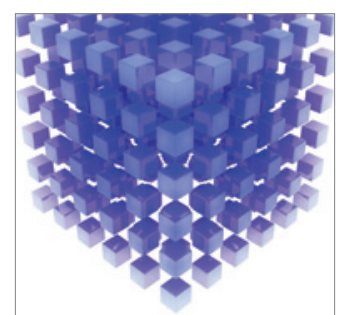

Mathematical Problems in Engineering
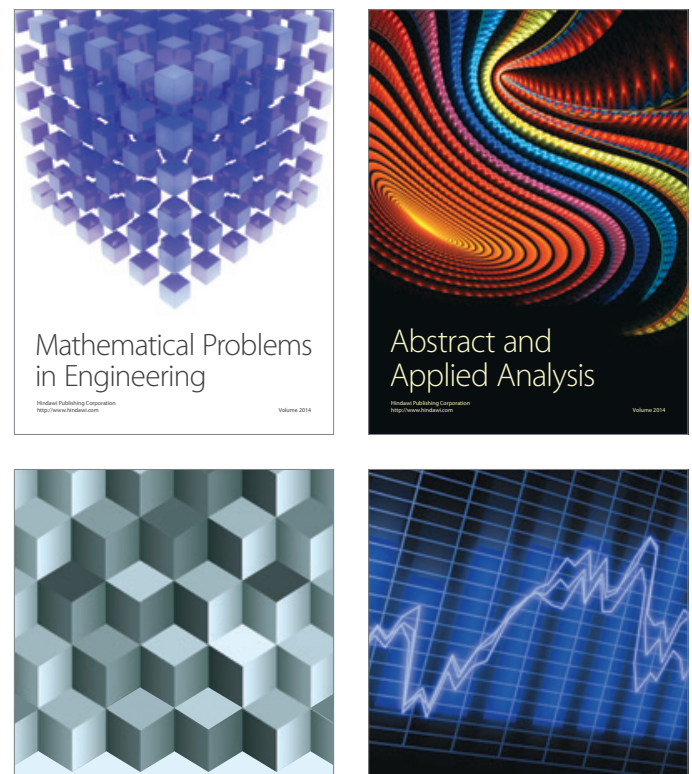

Journal of

Function Spaces

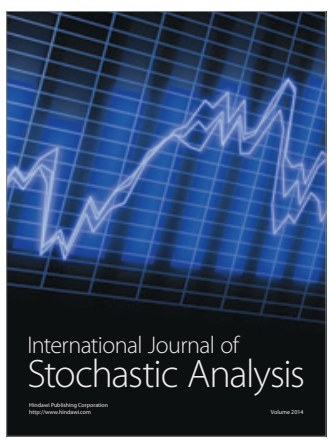

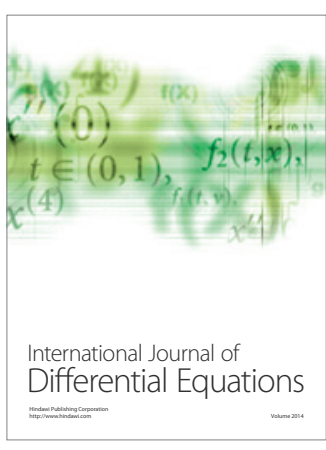
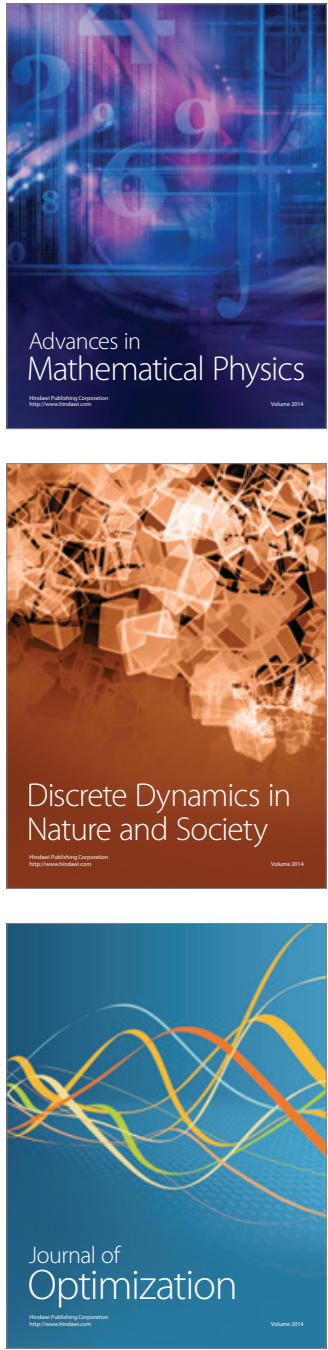